\title{
Casing Pipe Damage Detection with Optical Fiber Sensors: A Case Study in Oil Well Constructions
}

\author{
Zhi Zhou, ${ }^{1,2}$ Jianping He, ${ }^{1}$ Minghua Huang, ${ }^{1}$ Jun He, ${ }^{1}$ and Genda Chen ${ }^{2}$ \\ ${ }^{1}$ School of Civil Engineering, Harbin Institute of Technology, Harbin, Heilongjiang 150090, China \\ ${ }^{2}$ Center for Infrastructure Engineering Studies, Missouri University of Science and Technology, Rolla, MO 65409-0710, USA
}

Correspondence should be addressed to Zhi Zhou, zhouzhi@mst.edu

Received 14 October 2009; Accepted 2 December 2009

Academic Editor: Jinying Zhu

Copyright ( $) 2010$ Zhi Zhou et al. This is an open access article distributed under the Creative Commons Attribution License, which permits unrestricted use, distribution, and reproduction in any medium, provided the original work is properly cited.

\begin{abstract}
Casing pipes in oil well constructions may suddenly buckle inward as their inside and outside hydrostatic pressure difference increases. For the safety of construction workers and the steady development of oil industries, it is critically important to measure the stress state of a casing pipe. This study develops a rugged, real-time monitoring, and warning system that combines the distributed Brillouin Scattering Time Domain Reflectometry (BOTDR) and the discrete fiber Bragg grating (FBG) measurement. The BOTDR optical fiber sensors were embedded with no optical fiber splice joints in a fiber-reinforced polymer (FRP) rebar and the FBG sensors were wrapped in epoxy resins and glass clothes, both installed during the segmental construction of casing pipes. In situ tests indicate that the proposed sensing system and installation technique can survive the downhole driving process of casing pipes, withstand a harsh service environment, and remain intact with the casing pipes for compatible strain measurements. The relative error of the measured strains between the distributed and discrete sensors is less than $12 \%$. The FBG sensors successfully measured the maximum horizontal principal stress with a relative error of $6.7 \%$ in comparison with a cross multipole array acoustic instrument.
\end{abstract}

\section{Introduction}

Many oil and gas wells in China are drilled with highpressure water injections and shored with casing pipes bolted or welded together from many sections. Casing damage often occurs as a result of pipe corrosion, joint dislocation, and long-term water injection development. It represents the most important factor for unproductive oil and gas wells. By 2003, a total of 5400 casing pipes had been damaged, accounting for nearly $20 \%$ of all oil wells in the Shengli Oilfield in China. By 2005, more than 11,188 oil well casings or $18.54 \%$ of all oil wells in the Daqing Oilfield had collapsed. This casing damage resulted in the loss of tens of billions of Chinese Yuan $[1,2]$. The problems associated with casing damage continue to grow in Chinese Oilfields. Once damaged, most deeply buried casings are difficult to repair in practice. Therefore, the most effective way to maintain the operation of oil wells is to prevent casing pipes from collapsing, requiring a real-time monitoring and warning system for casing pipes.
Up to date, no cost-effective and reliable sensing technologies and installation techniques exist for long-term monitoring and evaluation of casing pipes. Traditional casing inspection techniques are not suitable for real-time monitoring of casing damage. Other damage detection techniques, such as the fiber downhole video logging tool, combined multifinger imaging and magnetic thickness tool, cross multipole array acoustic technology, and borehole ultrasonic imaging, operate at the detection or inspection level and monitor only the macromechanical deformation or breakage [3-6]. Since the 1990s, optical fiber sensing techniques, both locally high-precision FBG sensors and distributed Brillouin Scattering Time Domain Reflectometry (BOTDR) sensors, have been considered to be most promising for longterm structural health monitoring. They show significant advantages over conventional sensing technologies in terms of accuracy, durability, and sensing distance [7-12]. Oil wells are underground structures whose damages could be substantial, deeply-hidden, and random. Neither FBG nor BOTDR sensing technology along can meet the requirements 
for the effective monitoring of a casing pipe. FBG sensing technology can only give local information, and BOTDR sensing technology offers a low spatial resolution, low test accuracy, low sampling frequency, and high cost system for strain and temperature measurements. A combination of FBG and BOTDR systems, however, is a promising alternative for the real-time monitoring of casing pipes.

This paper proposes a real-time monitoring and early warning system for casing pipes in oil well operations. In this case, the strain/stress state and safety of casing pipes are monitored and evaluated by a combined FBG and BOTDR system. To improve the system robustness, one or two optical fibers (OFs) are embedded into a fiber reinforced polymer (FRP) bar with no optical fiber splice joints, referred to as an FRP-OF bar, to measure the strain distribution of a casing pipe. For casing pipe applications, the FBG and FRP$\mathrm{OF}$ bar installation techniques were also investigated. The effectiveness of the technique was validated by the in situ testing in Daqing oilfield.

\section{Optical Fiber Sensing Principle}

As two representative types of optical sensing technologies, FBG and BOTDR sensors have been recently applied to many field projects for structural health monitoring. Both the Bragg wavelength and the Brillouin frequency can be related to strain and temperature with calibration coefficients $[7,8,13,14]$. Without considering the cross-coupling effect of strain and temperature, the Bragg wavelength $\left(\Delta \lambda_{B}\right)$ and Brillouin frequency shift $\left(\Delta v_{B}\right)$ have been shown to be linearly dependant on strain $(\Delta \varepsilon)$ and temperature $(\Delta T)$ by (1) and (2), respectively,

$$
\begin{aligned}
& \Delta \lambda_{B}=\alpha_{\varepsilon} \Delta \varepsilon+\alpha_{T} \Delta T, \\
& \Delta \nu_{B}=C_{\varepsilon} \Delta \varepsilon+C_{T} \Delta T,
\end{aligned}
$$

where $\alpha_{\varepsilon}$ and $\alpha_{T}$ are the strain and temperature sensitivity coefficients of FBG sensors, respectively; $C_{\varepsilon}$ and $C_{T}$ are the strain and temperature sensitivity coefficients of BOTDR sensors, respectively. In this study, the FBGs used have $\alpha_{\varepsilon}=1.2 \mathrm{pm} / \mu \varepsilon$ and $\alpha_{T}=10.8 \mathrm{pm} /{ }^{\circ} \mathrm{C}$. SMF-28 optical fibers were used in BOTDR measurements which have $C_{\varepsilon}=$ $0.05 \mathrm{MHz} / \mu \varepsilon$ and $C_{T}=1.0 \mathrm{MHz} /{ }^{\circ} \mathrm{C}$.

\section{Fabrication of Long FRP-OF Bar}

The downhole environment and condition in which the in-service casing pipes of oil and gas wells operate are extremely harsh and complex. Each casing pipe could be kilometers long and must be made in situ by bolting or welding one modular section at a time. Therefore, the surface installation of conventional sensors will either be damaged during installation or have low signal-to-noise ratio due to signal loss over the long distance. In this study, a kilometerlong FRP bar was fabricated by embedding one or two optical fibers into the center of an FRP bar with no optical fiber splice joint. Several glass fibers were pulled from a pulley system, bathed in an epoxy basin, fed together with one or

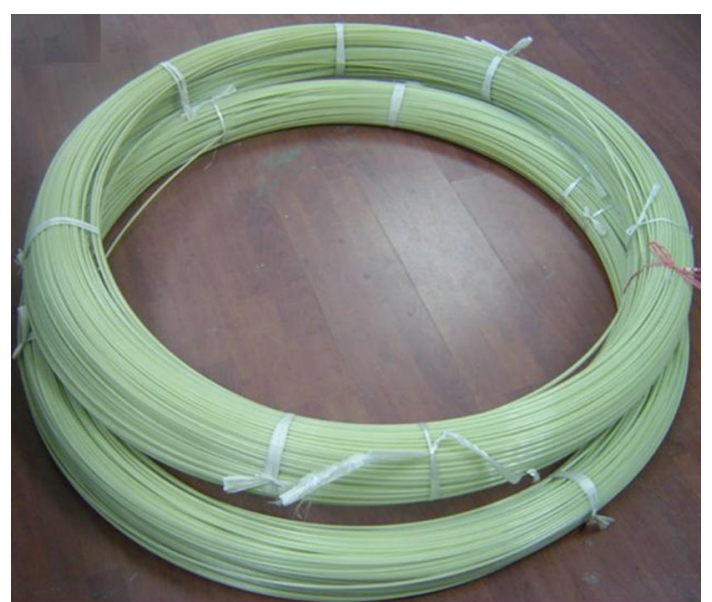

FIGURE 1: Finished product of FRP-OF bars.

two OFs at the center into the heating furnace, and finally pultruded through a rotating machine to form an FRP bar with embedded OFs as illustrated in Figure 1.

Figure 2 presents the sensing properties of an FRPOF bar used in this study. The Brillouin frequency shift (BFS) of the sensing bar has a good linear relationship with the applied strain and temperature. The linear fitting in Figures 2(a) and 2(b) has a correlation coefficients of 0.999 , and the slope of the linear regressions represents sensitivity coefficients of $0.050 \mathrm{MHz} / \mu \varepsilon$ and $1.263 \mathrm{MHz} /{ }^{\circ} \mathrm{C}$, respectively. In comparison with the sensitivity coefficients of its corresponding bare optical fiber, the temperature sensitivity coefficient is higher by $25 \%$, while the strain sensitivity coefficient keeps constant.

The fabricated FRP-OF bar with two optical fibers is suitable for both BOTDA (Brillouin Scattering Time Domain Analysis) and BOTDR measurements. The function of the sensing fiber is the same, which acts as transmission medium and sensor simultaneously. The difference is that for BOTDA it is a loop configure using two fiber ends; for BOTDR only one end is needed.

\section{Installation of Optical Fiber Sensors in Oilfield Applications}

4.1. Casing Pipe Damages and Monitoring System. Pump wells in the Daqing Oilfield, China, have been drilled with high-pressure water injection. During the past 20 years, many casing pipes were severely damaged at the oilfield damage. Figure 3 presents the statistics of casing pipe damages in Daqing Oilfield. It indicates that most of the damaged casing pipes took place in the N2, S1, and S2 index beds with nonoil reservoirs. This statistics can be used to guide the design of an optical fiber sensing system. For example, high-precision FBG strain measurements shall be taken in the N2 as well as in the S2-3 index bed according to Figure 3. The remaining beds can be monitored with the BOTDR sensing system for general strain distribution. 


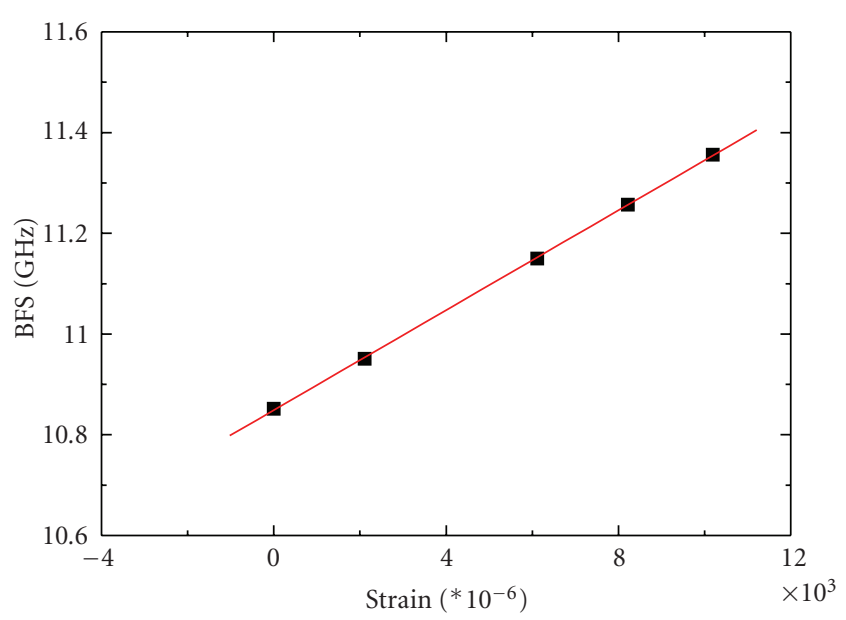

- Testing value

— Linear fitting

(a) Strain sensitivity coefficient

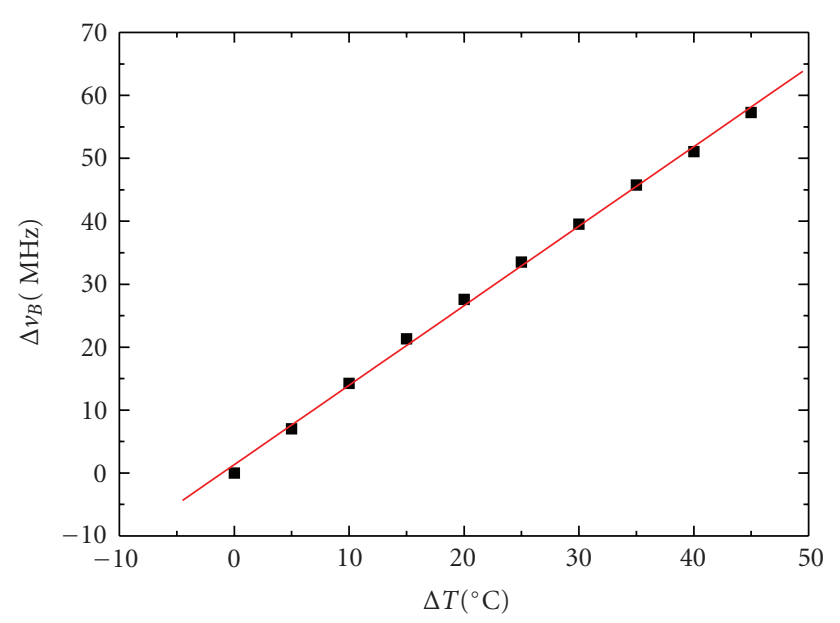

- Testing value Linear fitting

(b) Temperature sensitivity coefficient

FIgURE 2: Calibration of an FRP-OF bar.

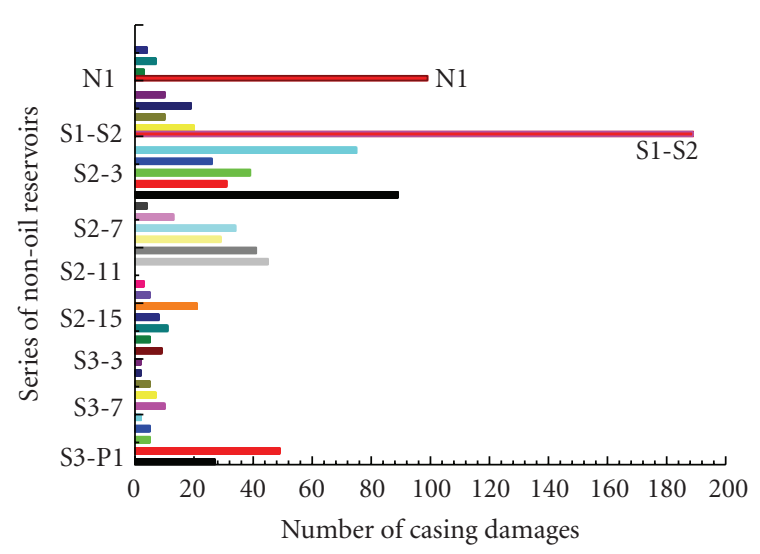

FIGURE 3: Statistics of oilfield well casing damages in various soil conditions.
To alert and prevent casing damages, both FBG and BOTDR sensors were installed on the casing pipe in the Oil Recovery Plant No.5, Daqing Oilfield Corporation Ltd. Figure 4 illustrates a sketch of the casing pipe monitoring system. BOTDR sensors or FRP-OF bars were installed on the surface of the casing pipe above NII or at non-oil reservoirs and FBG sensors were installed on the hot spot of N2 where casing damages often take place.

4.2. FRP-OF Bar Installation Technique. For a successful installation in practical applications, OF sensors must meet three requirements: (a) survive harsh underground environments and in-service conditions, (b) bond perfectly to the casing pipe to be monitored for accurate strain measurements, and (c) make it easy to integrate with other sensors and sensing systems.

An FRP-OF bar based on the Brillouin sensing technology can provide continuous strain/temperature information along the optical fiber. As shown in Figure 5(a), it was thus installed on the surface of the casing pipe over its entire length. To ensure that the FRP-OF bar deforms with the casing pipe, several stainless steel encircling hoops were used to fix the FRP-OF bar on the casing pipe at $2 \mathrm{~m}$ intervals. After putting in place in the downhole well, the casing pipe and the FRP-OF sensor were wrapped with cement mortar to enhance their deformation compatibility. Moreover, the two optical fibers were connected in series to form a measurement loop in the case of the BOTDA system. The bottom end of the FRP-OF bar or the position of the optical fiber splice joint must be well protected to prevent damage during the well downhole process. For that purpose, a stainless steel shell was used to cover the optical fiber splice joint, and the gap in the shell was sealed with an epoxy iron mixture, as illustrated in Figure 5(b).

Figure 6 shows the field installation of an FRP-OF bar and a casing pipe in the Daqing Oilfield. It involves three steps: lowering the casing into downhole, filling its outside gap with mud, and placing a mud circle for grouting. The process of oil well cementing involves injection of isolation fluid, cementing, water injection, pressing, decompression, and opposite well.

4.3. FBG Strain Sensor Installation. Four FBG strain sensors were installed at stress concentration areas of the casing pipe. Figure 7 illustrates their locations and field installation on a casing pipe in the Daqing Oilfield. They were distributed around the circumference of the pipe at $90^{\circ}$ intervals. For perfect bonding with the casing pipe, the installation surface for each FBG strain sensor must be polished and cleaned. The FBG strain sensors were then covered by a piece of epoxy glass cloth for corrosion protection and durability. For long-term strain/stress measurements, one additional FBG temperature sensor was installed near the FBG strain sensors for temperature compensation. To separate the strain effect, the FBG temperature sensor was inserted into a small steel tube that was filled with silicone fluid to enhance thermal conductivity.

The initial center wavelengths of the five FBG sensors must be at least $3 \mathrm{~nm}$ apart for reliable measurements. A 


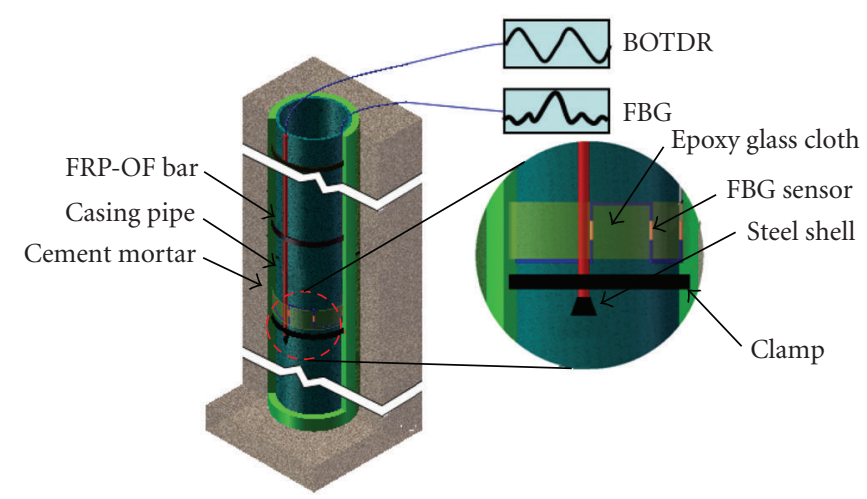

FIGURE 4: Sketch of a structural monitoring system for the casing pipe.

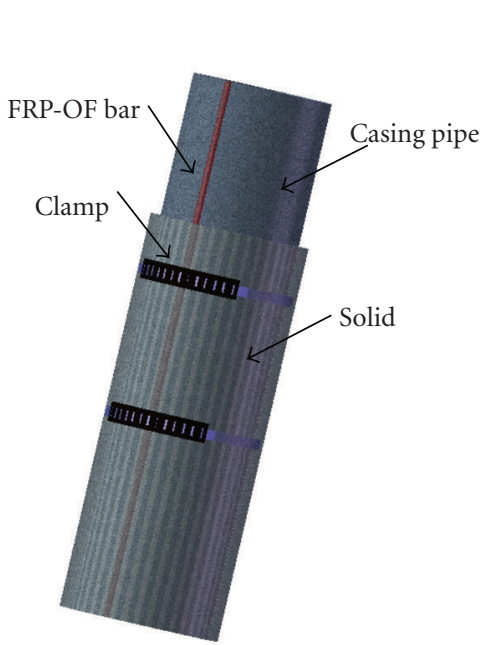

(a) Sketch of the FRP-OF bar installation

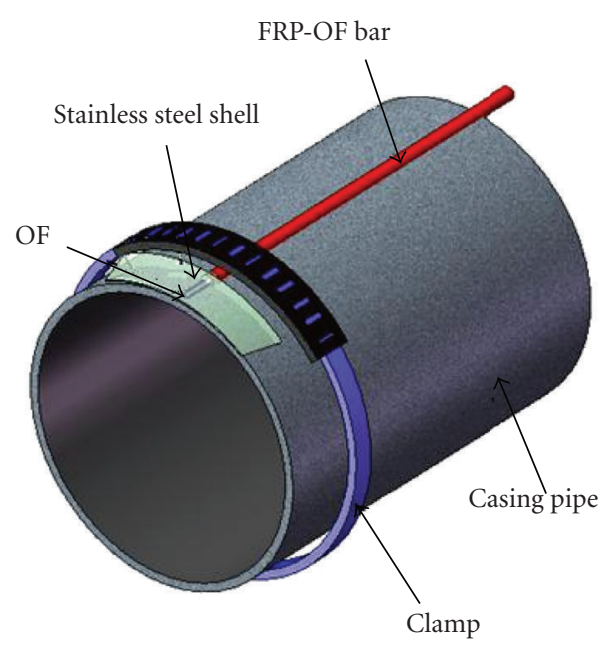

(b) Protective steel shell at a optical fiber splice joint

FIGURE 5: FRP-OF bar installation and protection.

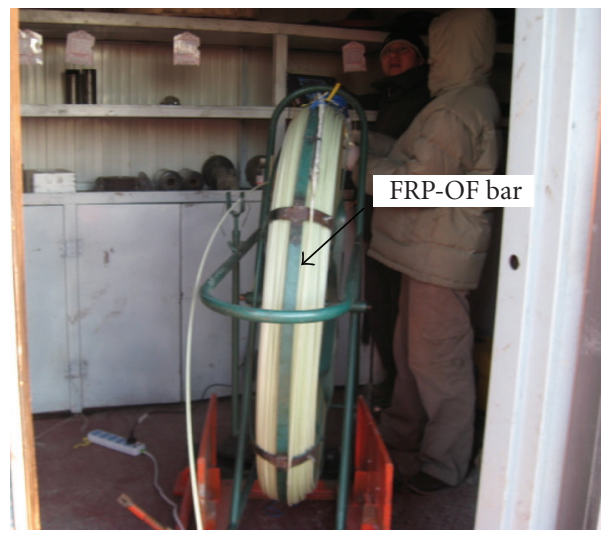

(a) Sketch of the FRP-OF bar

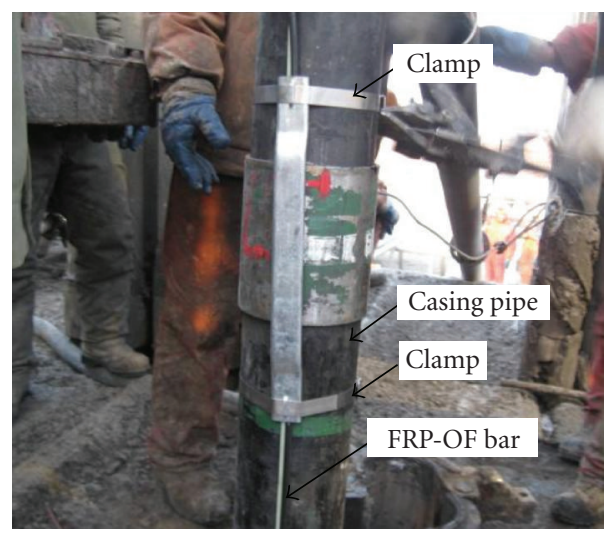

(b) Sketch of the FRP-OF bar installation

FIGURE 6: Sketch of the FRP-OF bar installation 


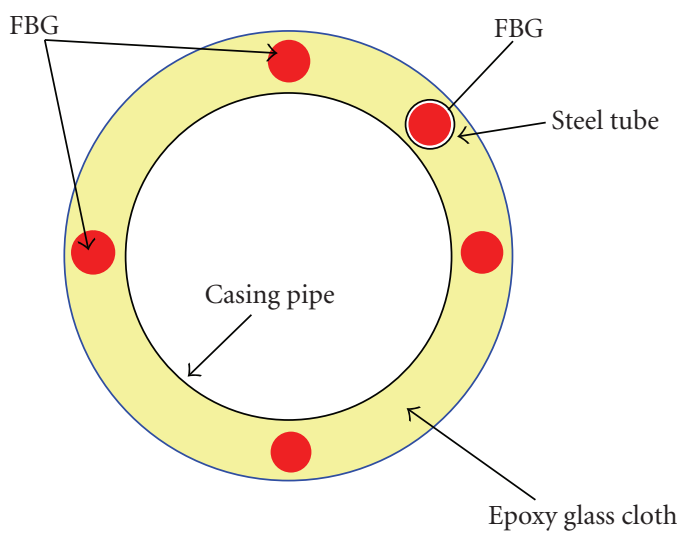

(a) FBG sensor distribution

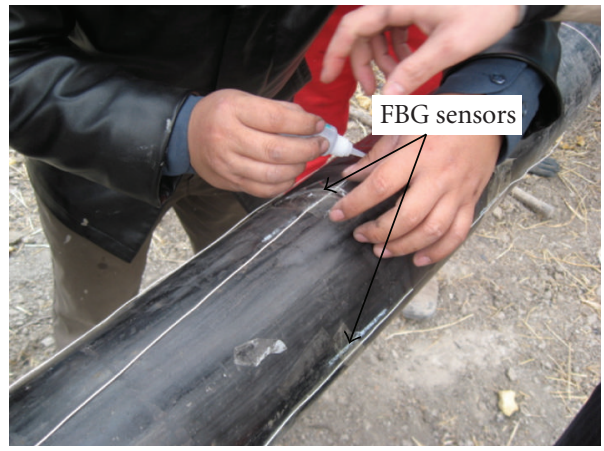

(b) FBG sensor locations

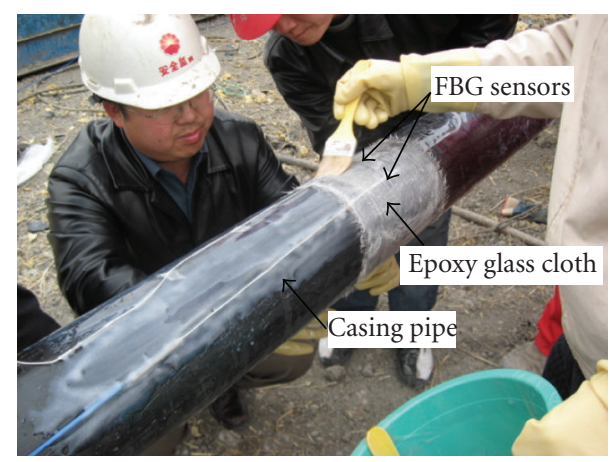

(c) Epoxy glass cloth wrapping

Figure 7: FBG sensor installation.
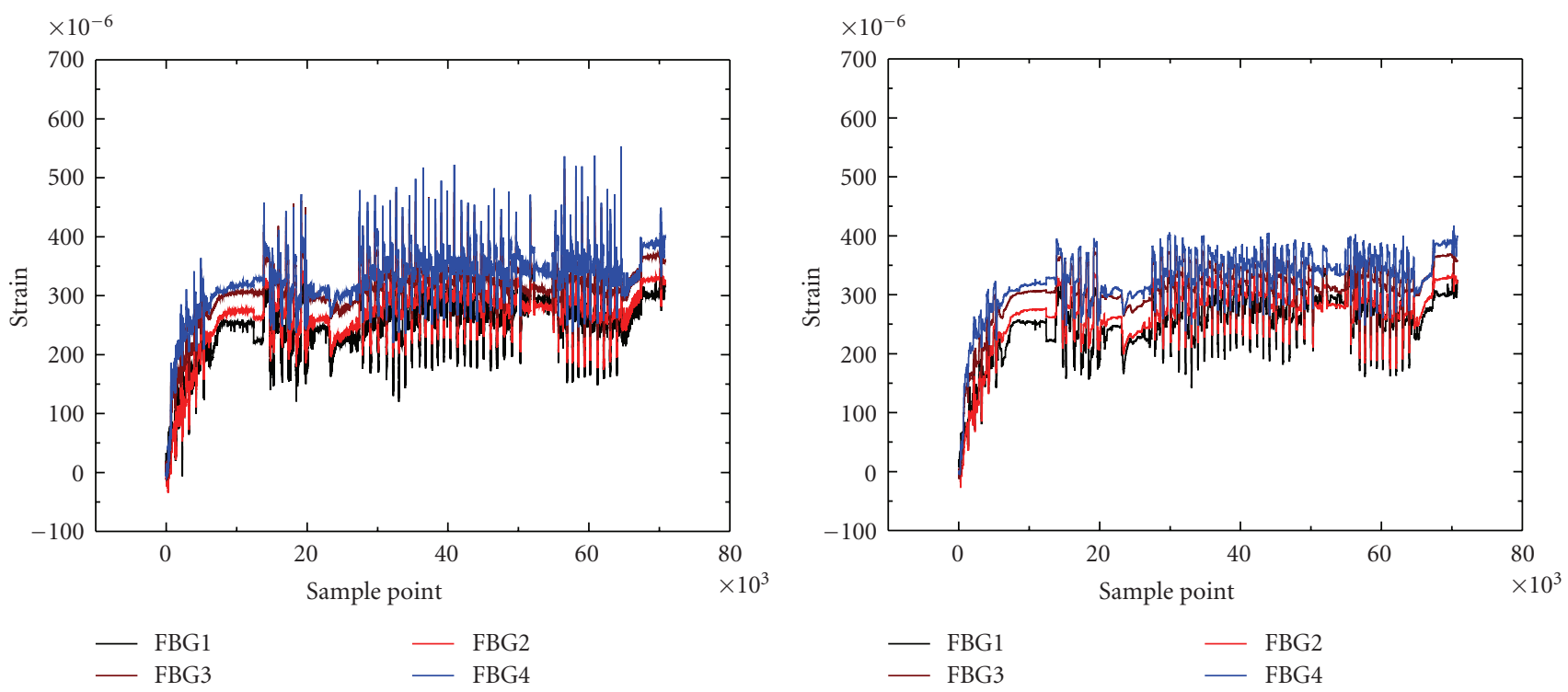

(a) Raw data

(b) Cleansed data 


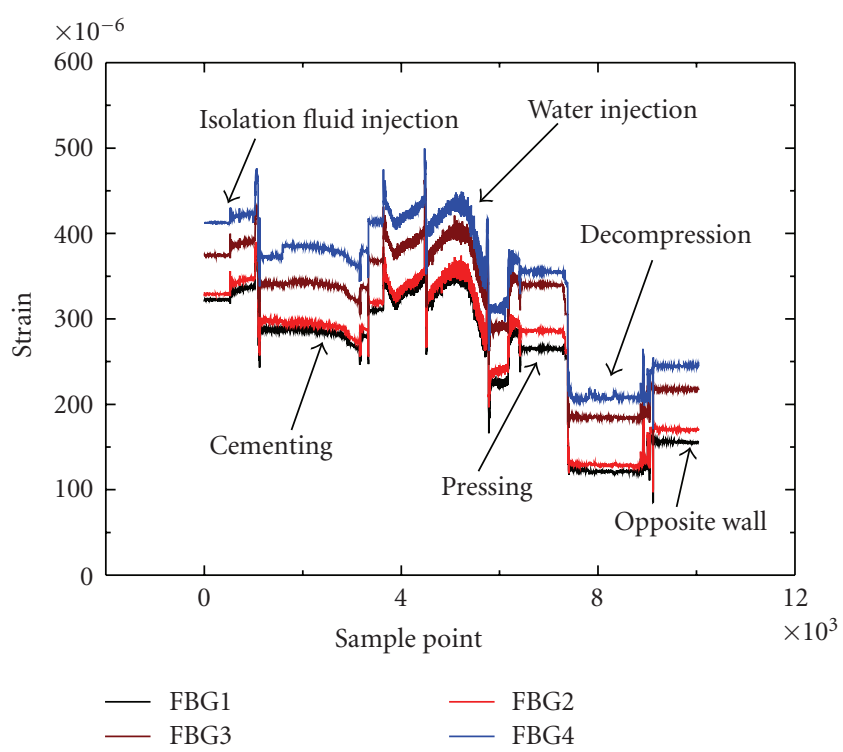

(a) Raw data

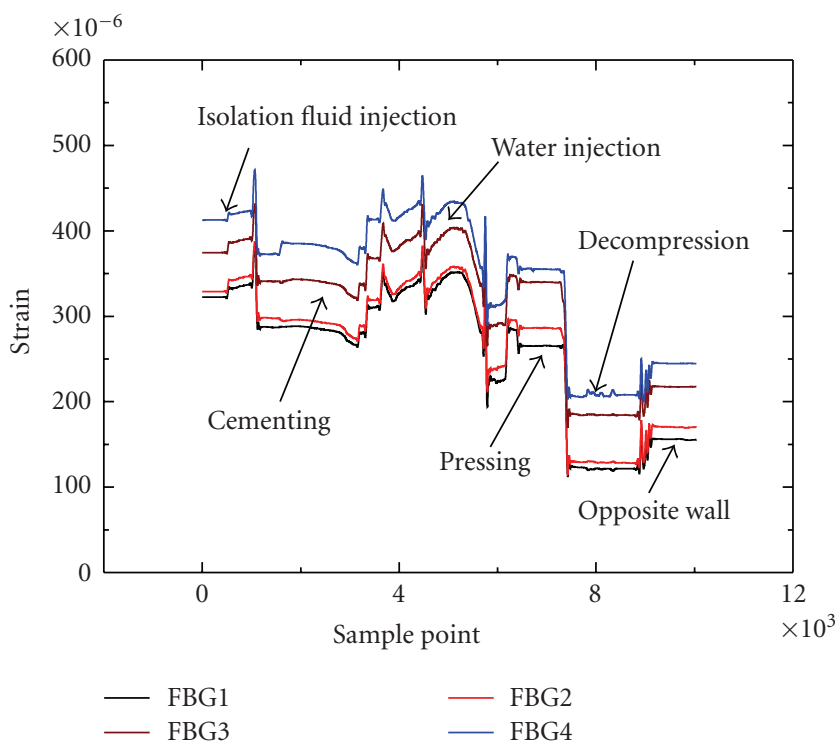

(b) Cleansed data

FIGURE 9: Strain measurements during grouting of the oil well.

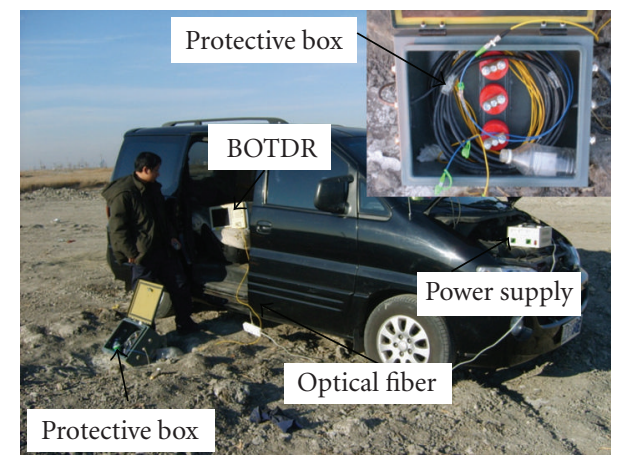

Figure 10: FRP-OF data acquisition.

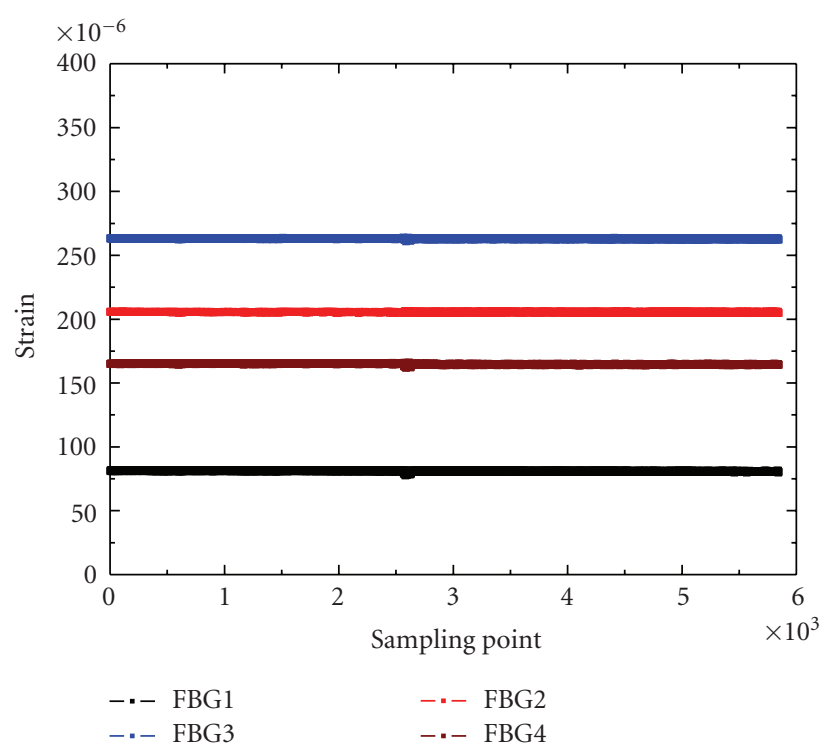

Figure 11: Strain data recorded in one day.

special fiber optical cable with $8 \mathrm{~mm}$ in diameter, protected by a steel strand, transmitted the temperature distribution for compensation to the strain measurements by the FRP-OF bar.

\section{Casing Damage Monitoring in the Daqing Oilfield}

To validate the installation techniques and measurement effectiveness of both FBG and BOTDR optical fiber sensor, three oil wells in the Daqing Oilfield were selected as test beds, including Xing10-5Bing3112, Xing10-5Bing3022, and Xing13-4-PB335. Each oil well was instrumented with the proposed optical sensors for in situ strain and temperature measurements in its casing pipe.

5.1. Strain Measurements at Xing10-5Bing3112 and Xing105Bing 3022. The two FRP-OF bars installed on the casing pipes at two oil wells are $818 \mathrm{~m}$ in Xing10-5Bing3112 and $838 \mathrm{~m}$ in Xing10-5Bing3022, respectively. The four FBG strain sensors and the FBG temperature sensor were installed in the area of N2 index bed of Xing10-5Bing3022 for high accuracy measurement.

Due to the limitations of the casing downhole technique and the measurement time required by the BOTDR, only the stress concentration areas of the casing pipe were monitored by FBG sensors during the casing downhole and oil well cementing process. The strains measured by the FBG sensors were recorded by an MOI si720 interrogator with a sample frequency of $5 \mathrm{~Hz}$ and measurement accuracy of $1 \mu \varepsilon$. Figures 8 (a) and 9(a) present the raw data of the temperaturecompensated strains measured by the FBG sensors during the processes of oil well casing and grouting. The raw data was contaminated by noise and thus cleansed by the db5 wavelet signal processing method [12]. The filtered signals as presented in Figures 8(b) and 9(b) show the significantly 
reduced "burr" components. This disappearance may reflect the stress state of the casing pipes during the casing downhole and oil well cementing process, and the maximum strain is about $500 \mu \varepsilon$. During both casing and grouting processes, the data points recorded by the four FBG strain sensors follow similar trends, indicating consistent and successful measurements from the case study.

After downhole casing and grouting, the two oil wells were put into operation. The strain data obtained from the FRP-OF bar was recorded by the demodulator BOTDR produced by NTT in Japan, which has a measuring accuracy of $\pm 40 \mu \varepsilon$ and minimum spatial resolution of $1 \mathrm{~m}$. Figure 10 shows in situ measurements of the strains of in-service casing pipes. As shown in Figure 11, the strain data points measured by the four FBG sensors all remained stable over a period of one day but varied from one to another sensor.

Figure 12 presents the strain increments measured by FRP-OF sensors on December 15-17, 2007 in addition to the initial strains presented in Figure 11. The measured strain increments remained stable, and all ranged from $-120 \mu \varepsilon$ to $+120 \mu \varepsilon$. The strains measured over three days by the FRP-OF sensor and its nearby FBG sensor at the stress concentration areas of the Xing10-5Bing3022 oil well are compared in Figure 13. It is observed that the strains measured by the FRP-OF sensor fluctuated around those measured by the FBG sensor, which changed little over the three days. This observation suggests that the FBG sensor is more accurate than the FRP-OF sensor based on the BOTDR technology. Their maximum relative error in strain measurement is approximately $12 \%$. Throughout the monitoring period, the strain state of in-service casing pipes was normal, showing no sign of inward buckling. The casing pipes were safe as confirmed by visual inspections.

5.2. Geostress Measurements and Perforation Experiments for Xing13-4-PB335. Perforation completion and positioning of the geostress orientation are two key factors in oil and gas explorations. To measure the geostress or circumferential stress, a total of 12 FBG strain sensors were installed around the circumference of the casing pipe of Xing134-PB335 oil well at $30^{\circ}$ intervals, and two FRP-OF bars of $1133 \mathrm{~m}$ long were installed along the casing pipe for stress distribution measurement. The orientations of the 12 FBGs were identified by a multiarm caliper logging tool. The orientation of FBG6 corresponding to the mark on the casing pipe as shown in Figure 14 is approximately $311^{\circ}$; the perforation orientations are $41^{\circ}$ and $221^{\circ}$ near the FBG9 and FBG3, respectively. As shown in Figures 15 and 16, the orientation of the maximum horizontal stress determined by the cross multipole array acoustic instrument (XMAC) and FBG sensors (before perforation) is approximately $94.67^{\circ}$ and $101^{\circ}$, respectively. The relative error between the two measuring techniques is approximately $6.7 \%$. The orientation of the maximum circumferential stress is vertical to that of perforating from the distribution of circumferential stress of the casing pipe before and after perforation completion measured by the FBG sensors as depicted in Figure 16, which agrees well with the actual stress state applied on the casing pipe.

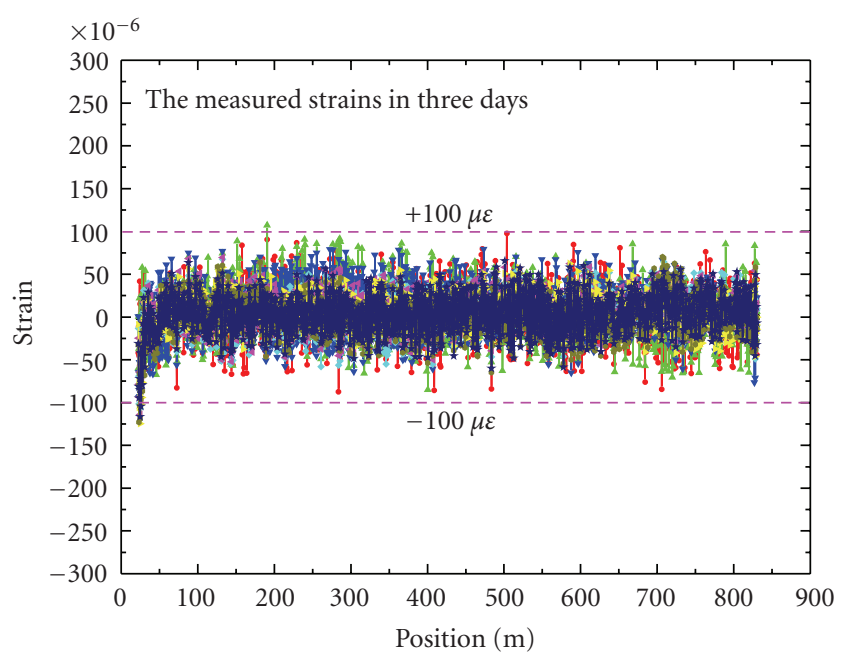

(a) Xing10-5Bing3112

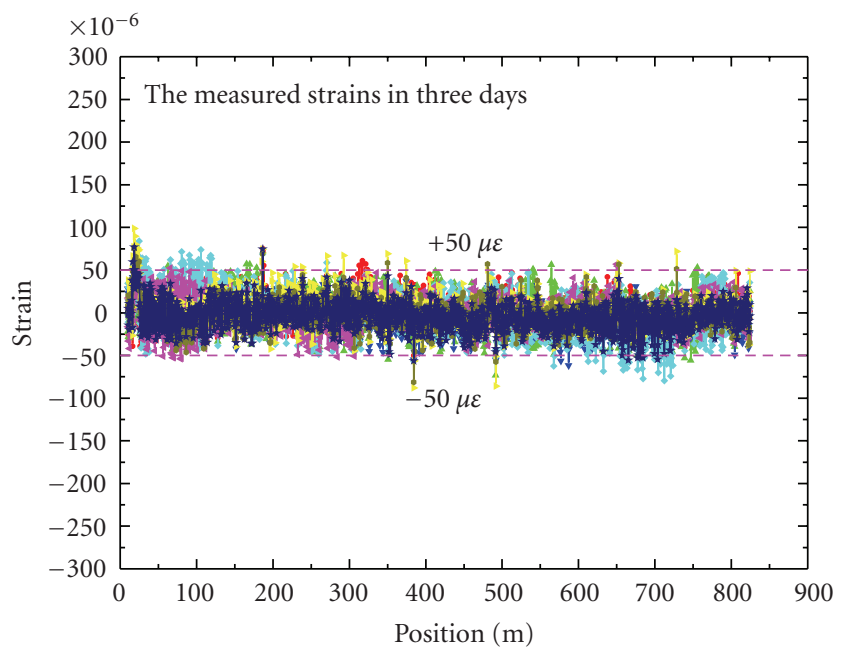

(b) Xing10-5Bing3022

FIGURE 12: Strain distribution of the casing pipe measured by FRPOF bar at two oil wells.

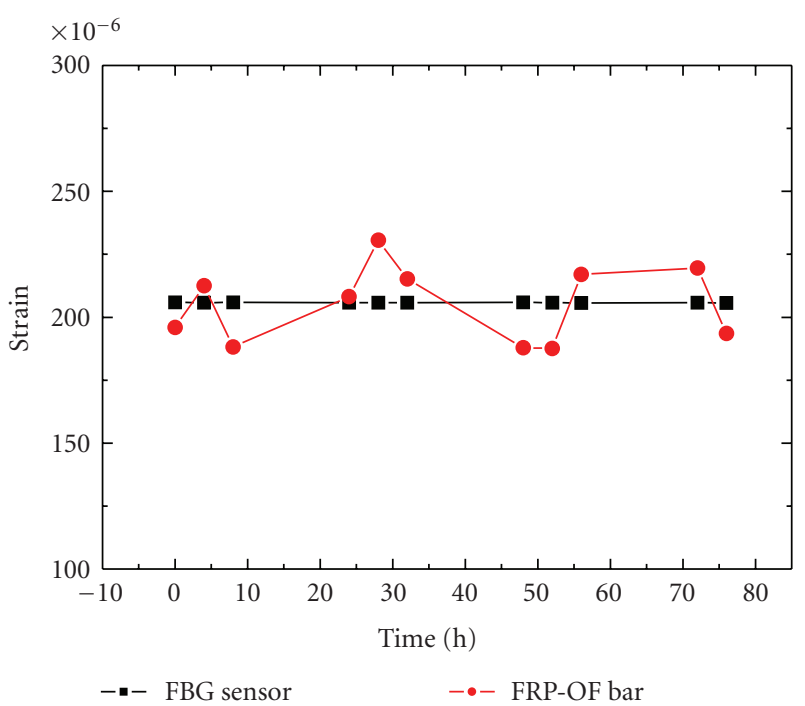

FIgURE 13: Strain comparison from FBG sensor and the FRP-OF bar. 


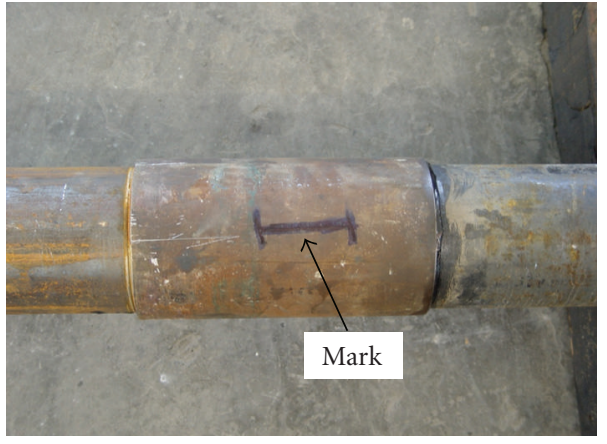

FIGURE 14: Orientation mark of casing pipe.

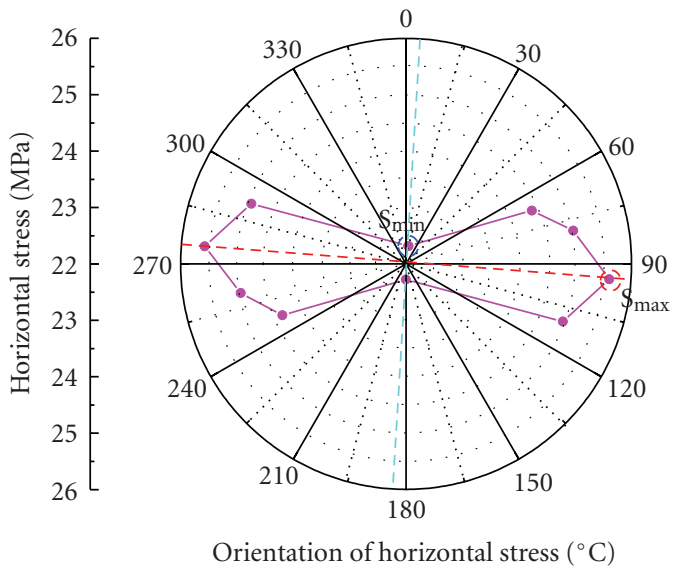

No.X13-4PB335

Position: $940-1171 \mathrm{~m}$

$S_{\max }: 94.67^{\circ} \mathrm{C}$

$\mathrm{S}_{\min }: 4.67^{\circ} \mathrm{C}$

FIGURE 15: The orientation of the maximum horizontal stress by XMAC.

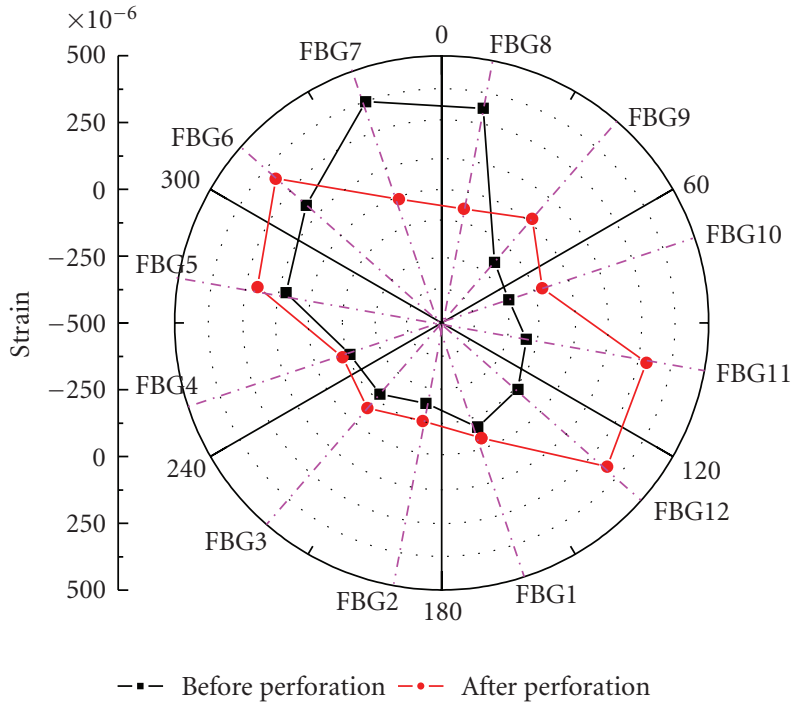

FIgURE 16: The distribution of casing pipe circumferential stress measured by FBG sensors.

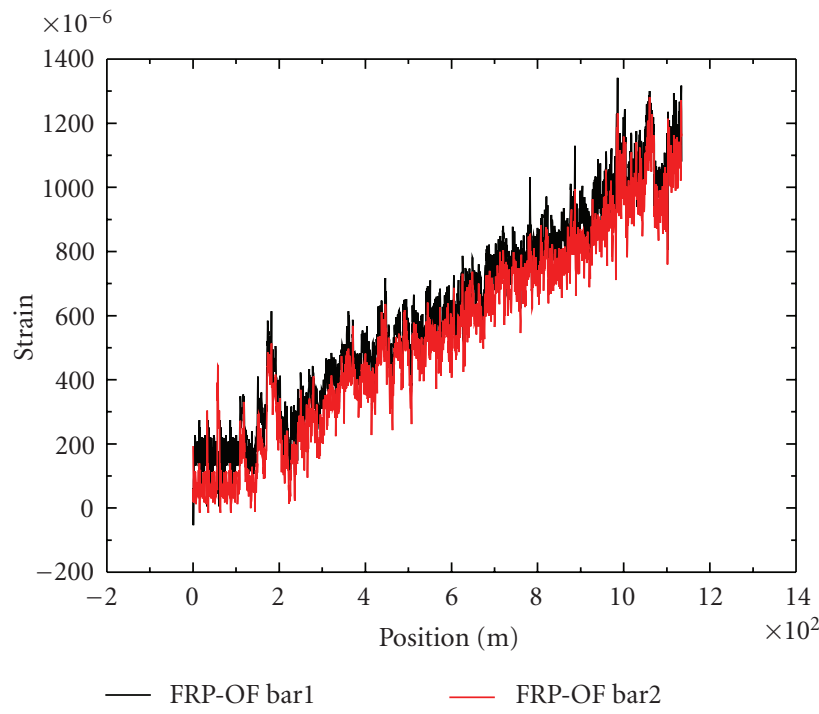

(a) Before perforation

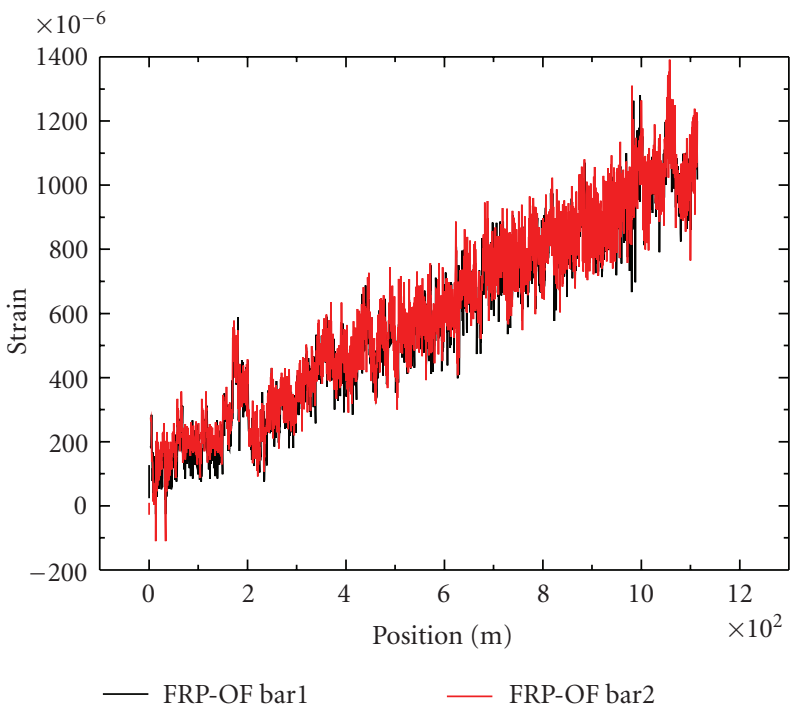

(b) After perforation

FIGURE 17: Strain distribution from the FRP-OF.

Figure 17 shows the strain distribution along the casing pipe before and after perforation completion, which were measured by the two FRP-OF sensors. The readings from the two sensors are consistent. The strain difference at any particular position ranges from $-200 \mu \varepsilon$ to $+200 \mu \varepsilon$, indicating that the axial strain of the casing pipe remains stable before and after the perforation completion. The average strain appears to be proportional to the distance from the ground surface due to gravity effects.

\section{Conclusions}

Based on the extensive strain data measured at three oil wells in the Daqing Oilfield and necessary analyses, the following conclusions are drawn. 
(a) This case study represents an innovative application of fiber optical sensors in the condition monitoring of casing pipes in oil well explorations. The experience demonstrated the feasibility of long-term structural health monitoring of oil wells with optical technologies.

(b) Both the FRP-OF and the FBG sensors wrapped in an epoxy glass cloth were stable and durable. They survived the casing and grouting processes of oil wells in a harsh construction environment and indicated that the installation procedure is effective.

(c) Both FRP-OF and FBG sensors can effectively monitor the stress/strain state of casing pipes with a relative error of less than $12 \%$. The FBG-measured distribution of circumferential stress in a casing pipe reveals the distribution of geostress. The relative error of the position for orientation of the maximum horizontal stress is approximately $6.7 \%$ between the FBG sensors and the XAMC technique.

\section{Acknowledgments}

Financial support to complete this study was provided by National Science Foundation of China under Grant nos. 10672048, 50978079, and 50538020 and by the National Scientific Support Project under Grant nos. 2006BAJ03B05 and 2006BAJ13B03.

\section{References}

[1] X. Y. Hu, Q. Y. Niu, and Y. Z. Wang, "Casing damage analysis and control technology," Environmental Protection of Oil and Gas Fileds, vol. 13, no. 3, pp. 35-37, 2003.

[2] Q. X. Liu, The casing condition logging and the study of the method to detect the casing stress, Doctor dissertation, China University of Geosciences, Beijing, China, 2006.

[3] L. X. Fu, L. J. Ma, and C. M. Qiao, "Cause and repair \& maintenance measures of casing in oil and water well," Petroleum Drilling Techniques, vol. 30, no. 4, pp. 53-56, 2002.

[4] Y. L. Li, Q. Li, and X. R. An, "Application of fiber downhole video logging tool in administering of casing damage well WLT," Petroleum Instruments, vol. 19, no. 4, pp. 20-23, 2005.

[5] F. L. Chen, X. Y. Cai, and Y. Jin, "Inspection and evaluation method of casing damages with multi-arm Caliper log," Well Logging Technology, vol. 29, no. 1, pp. 79-81, 2005.

[6] J. K. Hao, W. L. Liu, and Y. B. Li, "Application of MIT_MTT combination technology for casing detection in changqing oilfield," Well Logging Technology, vol. 30, no. 5, pp. 449-453, 2006.

[7] J. P. Ou, "Some recent advance of intelligent monitoring system for civil infrastructures in Mainland China," in Proceeding of the 1st International Conference on Structural Health Monitoring and Intelligent Infrastructures, pp. 131-144, 2003.

[8] Z. Zhou, Optical fiber bragg grating sensors and intelligent monitoring system in civil infrastructures, Doctor dissertation, Harbin Institute of Technology, Harbin, China, 2003.

[9] D. Inaudi and B. Glisic, "Development of distributed strain and temperature sensing cables," in Proceedings of the 17th International Conference on Optical Fibre Sensors, vol. 5855 of Proceedings of SPIE, pp. 222-225, May 2005.
[10] J. P. He and Z. Zhou, "Long-term monitoring of a civil defensive structure based on distributed Brillouin optical fiber sensor," Pacific Science Review, vol. 9, pp. 97-102, 2007.

[11] Z. Zhou, J.-P. He, H.-W. Jia, and J.-P. Ou, "Full scale Brillouin sensing technique based smart parallel wire stay cable," Journal of Optoelectronics Laser, vol. 20, no. 6, pp. 766-770, 2009.

[12] J. P. He, Full scale BOTDA/R distributed monitoring technology and its application in civil engineering, Doctor dissertation, Harbin Institute of Technology, Harbin, China, 2009.

[13] D. Culverhouse, F. Farahi, C. N. Pannell, and D. A. Jackson, "Potential of stimulated Brillouin scattering as sensing mechanism for distributed temperature sensors," Electronics Letters, vol. 25, no. 14, pp. 913-915, 1989.

[14] T. Horiguchi, T. Kurashima, and M. Tateda, "Tensile strain dependence of Brillouin frequency shift in silica optical fibers," IEEE Photonics Technology Letters, vol. 1, no. 5, pp. 107-108, 1989. 

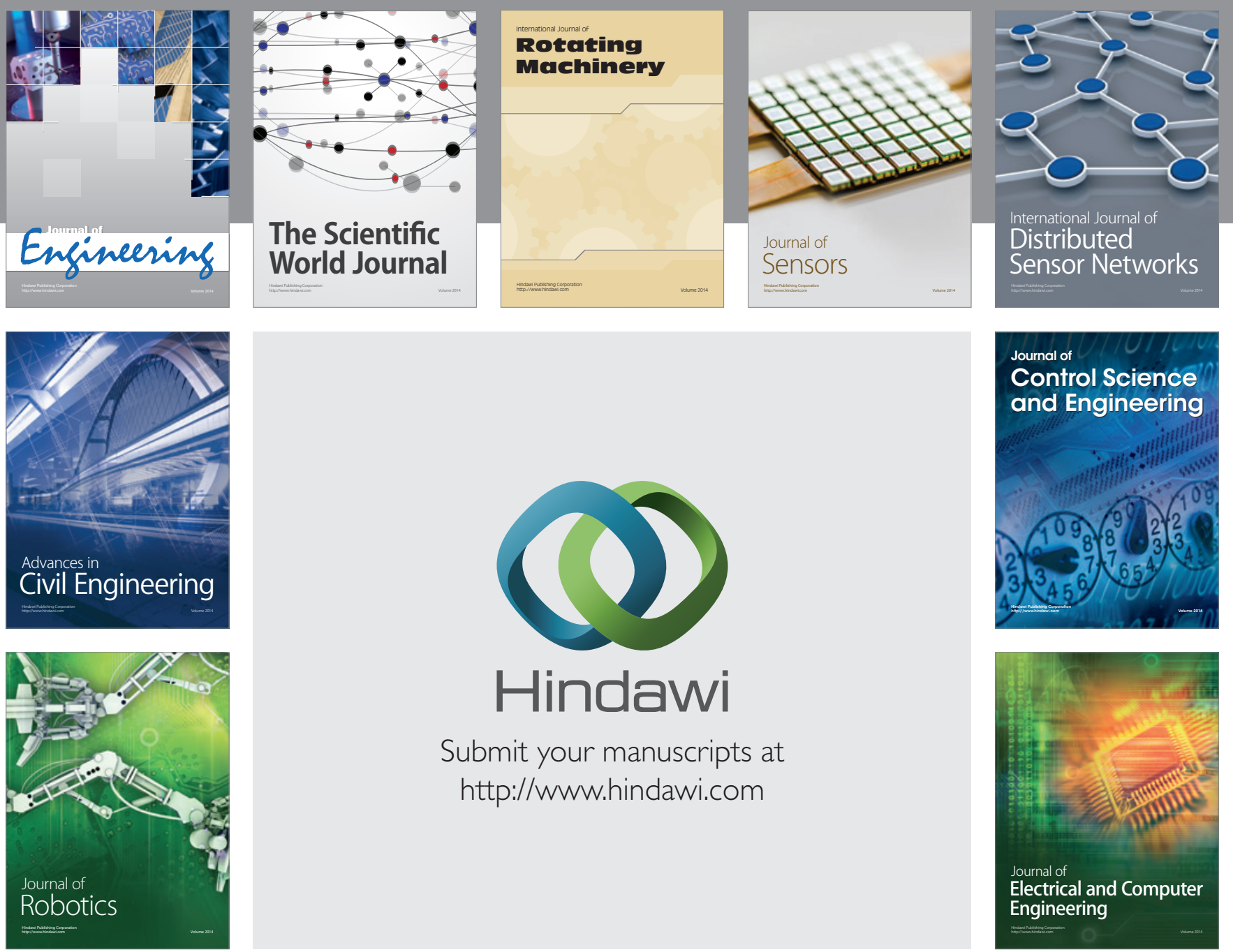

Submit your manuscripts at

http://www.hindawi.com
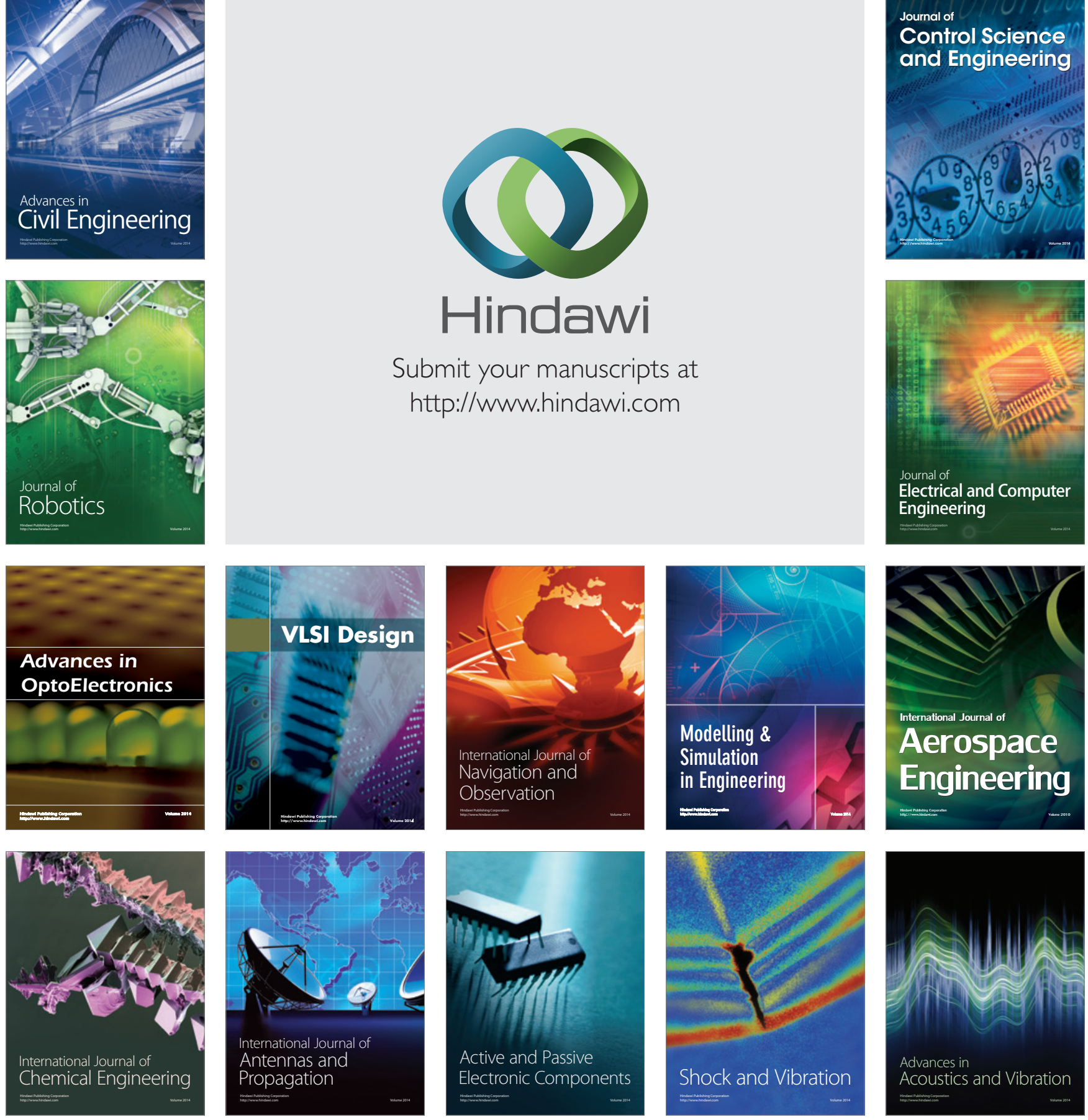